Borneo Journal of Sciences \& Technology, Volume (3), Issue (1), Pages: 07-14

DOI: http://doi.org/10.3570/bjost.2021.3.1-02

e-ISSN: 2672-7439

(c) 2018, UCTS Publisher.

Submitted: $18^{\text {th }}$ December $2019 \quad$ Accepted: $05^{\text {th }}$ May $2020 \quad$ Published: $31^{\text {st }}$ January 2021

\title{
Comparison between Modelling and Experimental Behaviour of Reinforced Concrete Beam with Transverse Circular Opening
}

\author{
Jen Hua Ling, Wen Yue Pao, Wen Kam Leong and How Teck Sia \\ School of Engineering and Technology, University College of Technology Sarawak (UCTS), \\ 96000 Sibu, Sarawak, Malaysia
}

\begin{abstract}
In this study, a finite element model was developed with the aid of a computer program, Ansys, to predict the behaviour of reinforced concrete beams with transverse openings under load. This method is more economical and less time consuming than conducting experimental tests, provided it can reliably predict the actual response of the beam. To determine the reliability of the model, an analysis was carried out on the results produced by the model. The predicted results were compared with the experimental results in terms of the load-displacement responses, the mechanical properties, and the parametric responses. The model was unable to reliably predict the entire response of the beam, particular during the elastic and yielding stages of the beam. Nevertheless, it predicted the ultimate state of the beam (e.g. ultimate capacity and total deformation) with a 75\% reliability. Should be model be used for further research studies or industrial applications, it should be used with cautions.
\end{abstract}

Keywords: Reinforced Concrete Beam, Circular Transverse Opening, Flexural and Shear Load, Finite Element Model.

\section{INTRODUCTION}

Transverse opening is normally provided in a reinforced concrete beam when there is limited ceiling space underneath the beam for the crossing of building services like pipes and ducts. Instead of crossing underneath, it allows the services to pass through the beam.

The opening changes the cross-sectional configuration of a beam, and hence, alters its behaviour [1]. It disrupts the flow of stress within a beam and leads to the concentration of stress surrounding it $[2,3]$. Thus, such beams generally have a lower strength, stiffness, and ductility than the normal RC beam [2, 4-9].

The beam performance was found affected by the number, size, shape, and position of the opening. For a higher strength of a beam, the opening should be (a) small [10-11], (b) without any sharp edge [12-14], and (c) placed at the low shear region [15].

The behaviour of beams with transverse openings is rather complex [1]. It is difficult to accurately predict its response through the derivation of equations. The actual response is normally acquired through experimental tests, which is rather costly and time-consuming.

Alternatively, it can be simulated through numerical modelling. This is provided the model can reliably predict the response of the beam. Otherwise, designing based on the simulated results can be quite dangerous.

In this study, a finite element model was developed with the aid of a computer program, Ansys, to simulate an experimental test conducted by Tang $(2018)[16,17]$ on reinforced concrete beams with circular transverse openings under load. The model was compared with the experimental results to determine its reliability.

\section{MATERIALS AND METHODS}

\section{Specimen Details}

A finite element model was used to simulate a four-point load test conducted on 8 reinforced concrete beam specimens, comprising 2 solid beams, 3 beams with openings at the support, and another 3 at the mid-span.

The details of the beam are: (Figure 1)

Dimension $: 150 \mathrm{~mm} \times 300 \mathrm{~mm} \times 1650 \mathrm{~mm}$

Clear span $\quad: 1500 \mathrm{~mm}$

Reinforcements : Top bars, 2T10

: Bottom bars, 2T12

: Stirrup, R8 - 250 or 150

Concrete cover $\quad: 25 \mathrm{~mm}$ (all sides) 


\section{Comparison between Modelling and Experimental Behaviour of Reinforced Concrete Beam with Transverse Circular Opening}

The position, $x$, and size, $d$, of the opening, the position of the point load, $a$, and the shear reinforcement of each specimen are given in Table 1

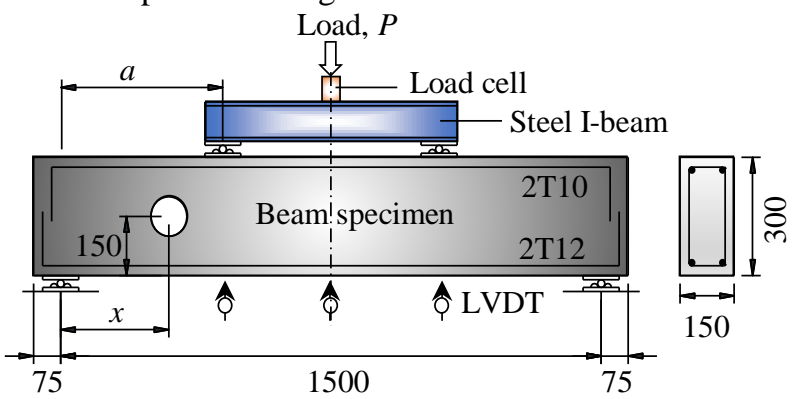

Figure 1: Test setup (dimension in $\mathrm{mm}$ ) [17]

Table 1: Specimen details (Refer to Figure 1) [17]

\begin{tabular}{lcccc}
\hline Specimen & $\begin{array}{c}d \\
(\mathrm{~mm})\end{array}$ & $\begin{array}{c}x \\
(\mathrm{~mm})\end{array}$ & $\begin{array}{c}a \\
(\mathrm{~mm})\end{array}$ & Stirrup \\
\hline $\mathrm{C} 1 / \mathrm{S}$ & - & - & 500 & $\mathrm{R} 8-250$ \\
$\mathrm{C} 2 / \mathrm{F}$ & - & - & 600 & $\mathrm{R} 8-150$ \\
$\mathrm{~S} 1 / 100$ & 100 & 300 & 500 & $\mathrm{R} 8-250$ \\
$\mathrm{~S} 2 / 75$ & 75 & 300 & 500 & $\mathrm{R} 8-250$ \\
$\mathrm{~S} 3 / 50$ & 50 & 300 & 500 & $\mathrm{R} 8-250$ \\
$\mathrm{~F} 1 / 100$ & 100 & 750 & 600 & $\mathrm{R} 8-150$ \\
$\mathrm{~F} 2 / 75$ & 75 & 750 & 600 & $\mathrm{R} 8-150$ \\
$\mathrm{~F} 3 / 50$ & 50 & 750 & 600 & $\mathrm{R} 8-150$ \\
\hline
\end{tabular}

${ }^{1} \mathrm{C}$-control, $S-$ shear, $F-$ flexural

The material properties of the model are given in Table 2. The model ignored the Polyvinyl Chloride (PVC) pipe used to create the transverse opening in the beam. It was assumed contributing no strength to the beam.

Table 2: Material properties of the model

\begin{tabular}{lccc}
\hline & Concrete & Rebar & Stirrup \\
\hline $\begin{array}{l}\text { Element } \\
\text { Young modulus, } E \\
\left(\mathrm{~N} / \mathrm{mm}^{2}\right)\end{array}$ & Solid65 & Link180 & Link180 \\
$\begin{array}{l}\text { Poisson ratio } \\
\text { Density, } \rho\left(\mathrm{kg} / \mathrm{m}^{3}\right)\end{array}$ & 0.2 & 200,000 & 200,000 \\
$\begin{array}{l}\text { Specified tensle } \\
\text { yield strength, } f_{y}\end{array}$ & - & 0.3 & 0.3 \\
$\left(\mathrm{~N} / \mathrm{mm}^{2}\right)$ & & 500 & 250 \\
$\begin{array}{l}\text { Compressive } \\
\text { strength, } \\
\left(\mathrm{N} / \mathrm{mm}^{2}\right)\end{array}$ & 25 & - & - \\
\hline
\end{tabular}

Figure 2 shows the typical models of the beams with and without opening in Ansys. Rectangle and line geometries were assigned to represent the concrete beam and steel reinforcements, respectively.

The tetrahedron meshing was used (Figure 3). The meshing size was determined after several trails until the predicted results were (a) reaching constant values and (b) close to the experimental results, as given in Table 3

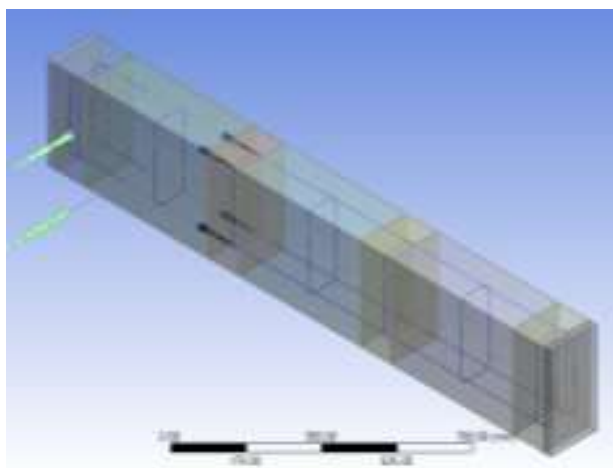

(a) Beam without opening $(\mathrm{C} 1 / \mathrm{S})$

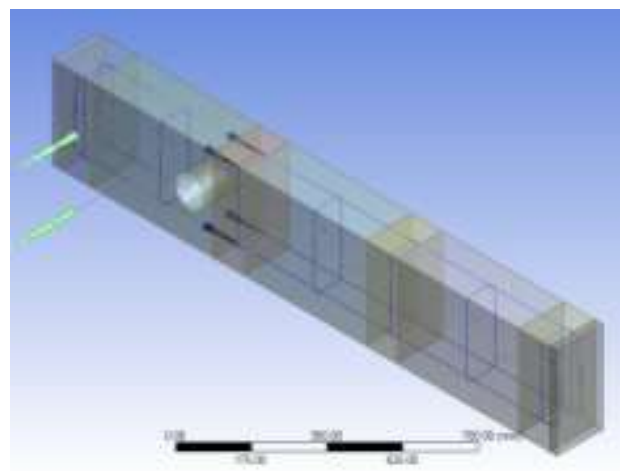

(b) Beam without opening (S1/100)

Figure 2 Typical beam models

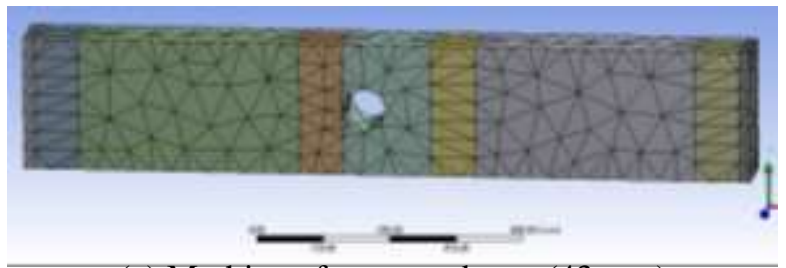

(a) Meshing of concrete beam (43 mm)

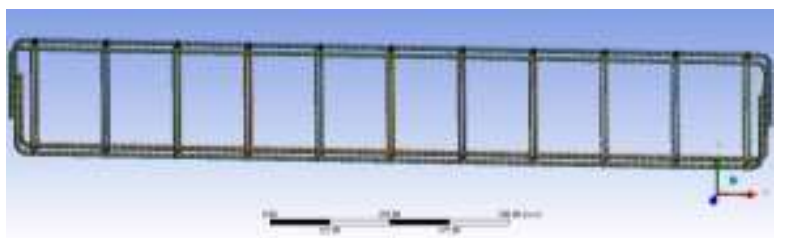

(b) Meshing of reinforcement $(2 \mathrm{~mm})$

Figure 3 Meshing of beam model

Table 3: Meshing size of each specimen (mm)

\begin{tabular}{ccc}
\hline Specimen & Concrete & Rebar \\
\hline C $1 / \mathrm{S}$ & 60 & 1 \\
$\mathrm{C} 2 / \mathrm{F}$ & 60 & 1 \\
$\mathrm{~S} 1 / 100$ & 33 & 1 \\
$\mathrm{~S} 2 / 75$ & 32 & 2 \\
$\mathrm{~S} 3 / 50$ & 40 & 1 \\
$\mathrm{~F} 1 / 100$ & 43 & 2 \\
$\mathrm{~F} 2 / 75$ & 60 & 3 \\
$\mathrm{~F} 3 / 50$ & 58 & 3 \\
\hline
\end{tabular}




\section{Comparison between Modelling and Experimental Behaviour of Reinforced Concrete Beam with Transverse}

Circular Opening

In Ansys, the applied load was progressively increased and the computed beam deformation was recorded. The beam was considered failed when (a) Ansys presented an illogical shape of the beam, or (b) an unrealistically large deflection was obtained (Figure 4).

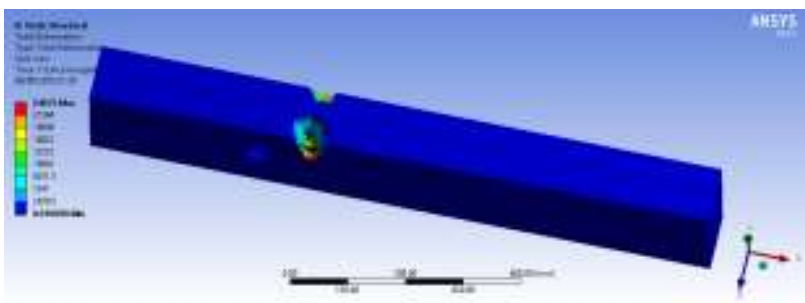

Figure 4: Failure of beam in Ansys

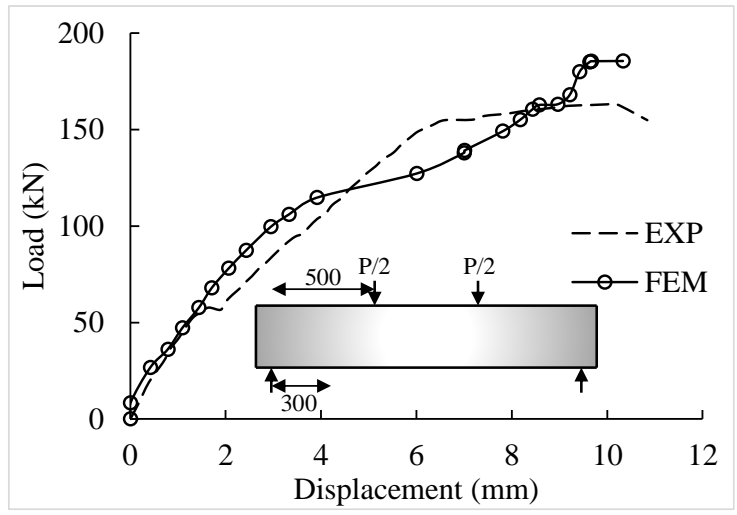

(a) Specimen $\mathrm{C} 1 / \mathrm{S}$

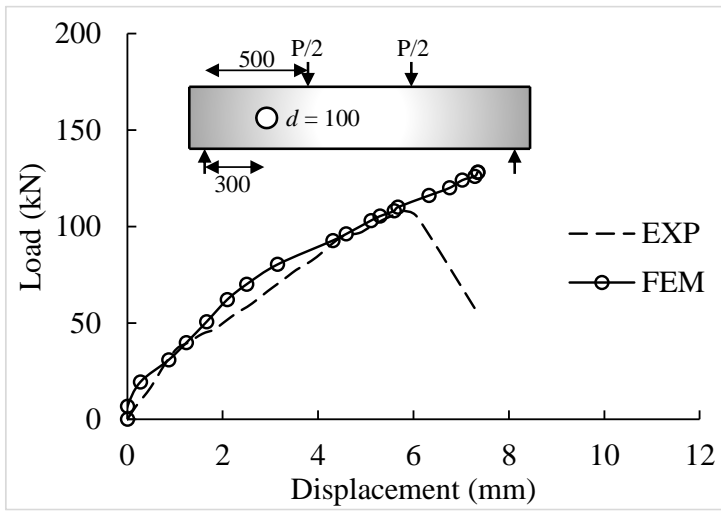

(c) Specimen S1/100

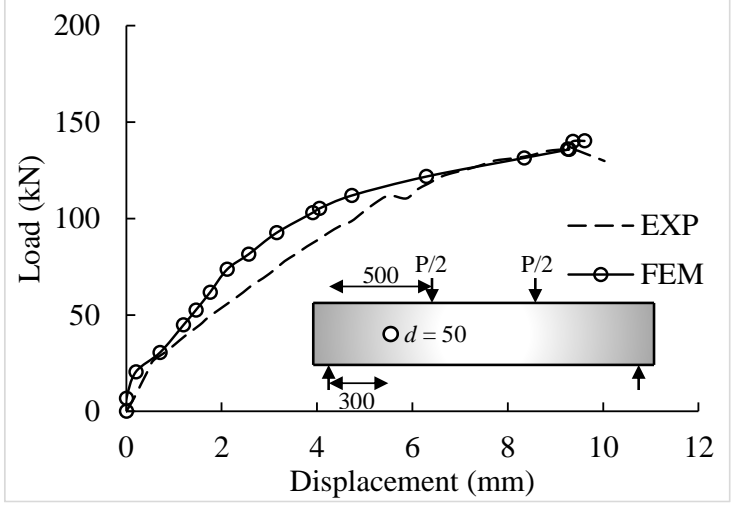

(e) Specimen S3/50

\section{RESULTS AND DISCUSSION}

The response simulated by the model were validated against the experimental results in terms of (a) loaddisplacement response, (b) mechanical properties, and (c) parametric response.

\section{Load-displacement response}

Figure 5 compares the load-displacement $(P-\delta)$ responses of the model and the experimental test. Both curves were quite close to each other. However, their trend (Figures 6(a) and (b)) and deflection (Figure 6(c)) varied.

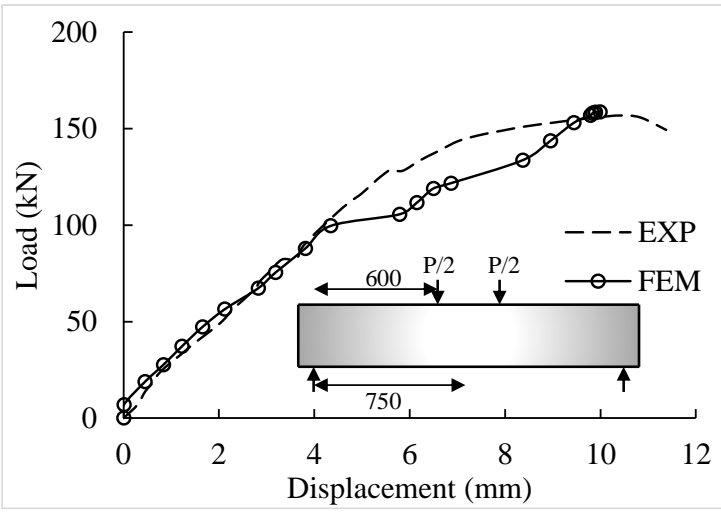

(b) Specimen C2/F

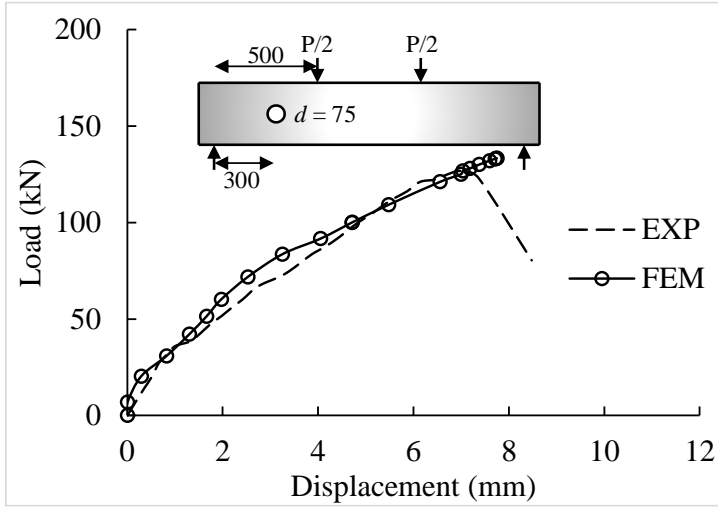

(d) Specimen S2/75

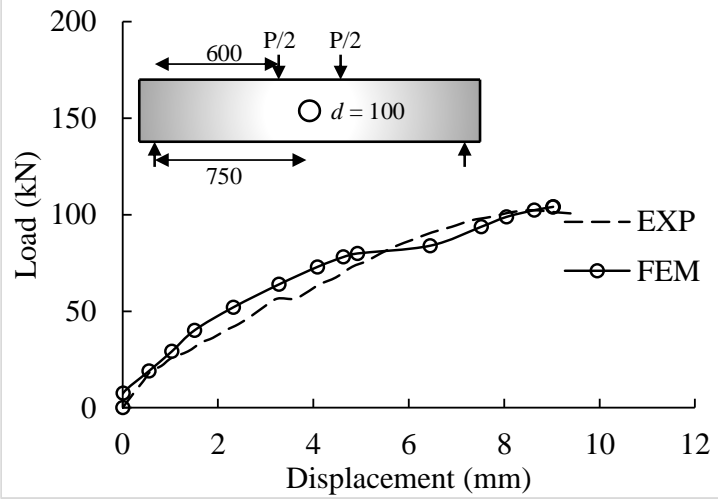

(f) Specimen F1/100

Figure 5: Comparison of the modelled and experimental load-displacement responses 


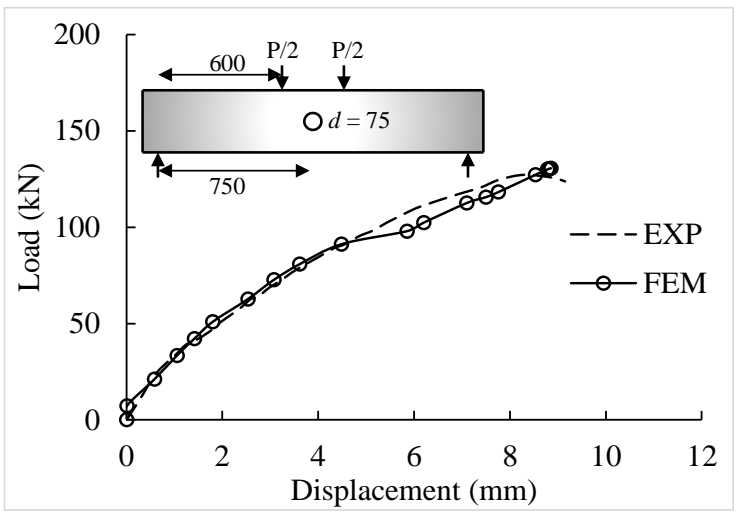

(g) Specimen F2/75

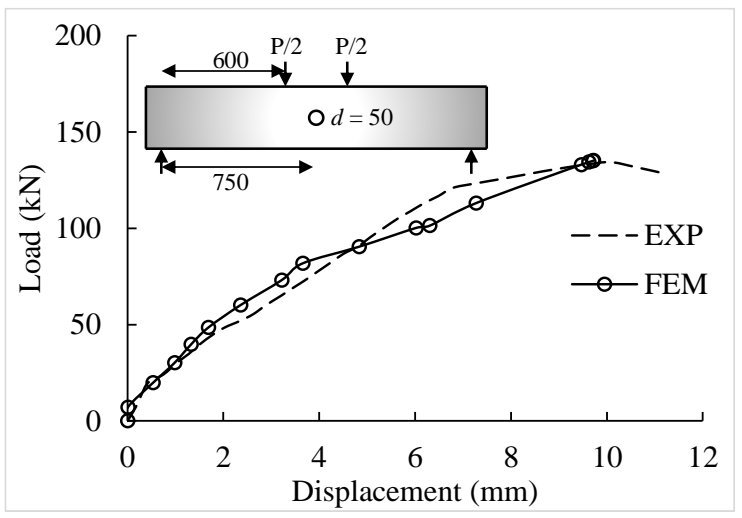

(h) Specimen F3/50

Figure 5: Comparison of the modelled and experimental load-displacement responses (Cont.)

From Figure 6(a), the model predicted the beam to response in 5 stages. It initiated with high stiffness in Stage A, as represented by the gradient of the curves. Then, the stiffness decreased progressively in Stages B and C, regained slightly in Stage D, and eventually, drastically decreased in Stage E. The beam may fail at any stage depending on its capacity (Figure 5).

In the experiment, the beam underwent 3 stages (Figure 6(b)). It possessed a high stiffness in Stage I, and progressively decreased in Stages II and III. According to Ling et. al (2019) [17], the beam cracked, yielded and failed at the end of Stages I, II and III, respectively.

The predicted deflection deferred slightly from the experimental test (Figure 6(c)). Initially, the model predicted a slower development of deflection. At Point "i", it outran the experimental results, and then, being overtaken again by the experimental results at Point "ii".

From Figure 5, the points "i" and "ii" generally occurred around $100 \mathrm{kN}$ and $120 \mathrm{kN}$, respectively. A larger variation of deflection was found in the solid beam and the beams with a smaller opening. This implied that the model was less accurate in predicting the solid beams and the beams closely resembled the solid beams.

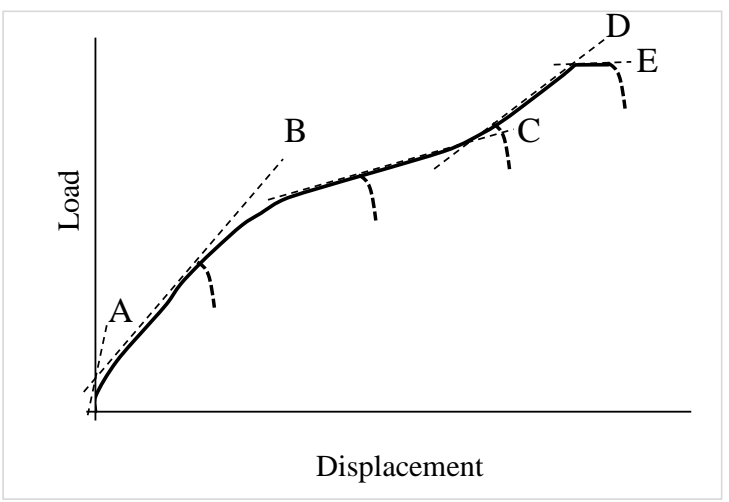

(a) FEM response

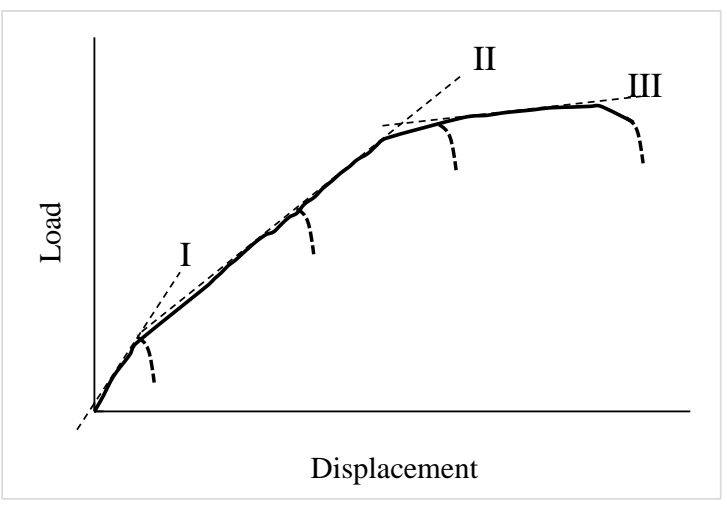

(b) Experimental response

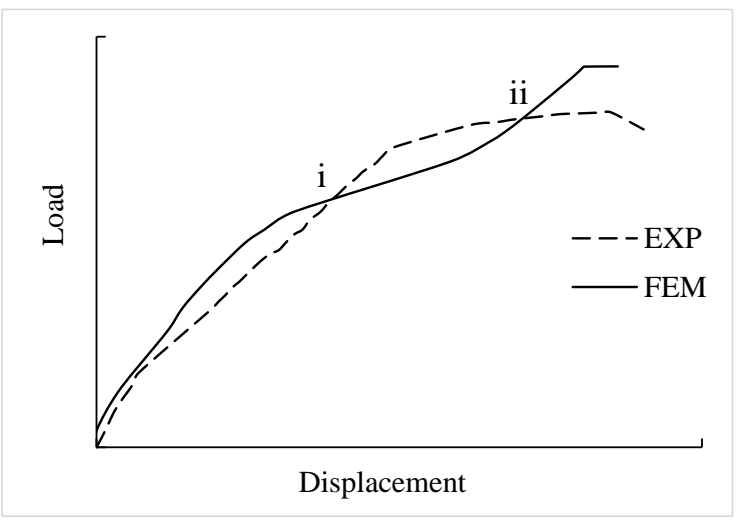

(c) Combined response

Figure 6: Typical load-displacement response

\section{Mechanical properties}

Figure 7 demonstrates the computation of the mechanical properties of the beam from the $P-\delta$ curves. The highest point of the curve was the ultimate capacity of the beam, $P_{u}$. The corresponding value on the x-axis was the total displacement of the beam, $\delta_{u}$.

Two horizontal lines were then drawn at the point $P_{u}$ and 0.75 times $P_{u}$. The $0.75 P_{u}$ line intercepted the $P$ $\delta$ curve at Point "A". A straight line was drawn from the Origin "O" to Point "A" and extended to intercept with the $P_{u}$ line at Point "B" (Figure 7). The yield point (Point 


\section{Comparison between Modelling and Experimental Behaviour of Reinforced Concrete Beam with Transverse Circular Opening}

"C") on the $P-\delta$ curve just below Point "B". The secant stiffness, $E$, would be the gradient of the line OA.

The predicted results were then compared with the experimental results. The predicted results were considered reliable when (a) the variation between the two results were within $\pm 10 \%$, and (b) a majority of the specimens $(\geq 80 \%)$ fulfilled the criteria.

For that, a reliability ratio, $R_{r}$, was computed by dividing the predicted results by the experimental results (Table 4). The ratio ranging from 0.9 to 1.1 represented a satisfactory prediction, and the percentage of satisfactory prediction should be more than $80 \%$ to signify a reliable prediction of a mechanical property of beam.

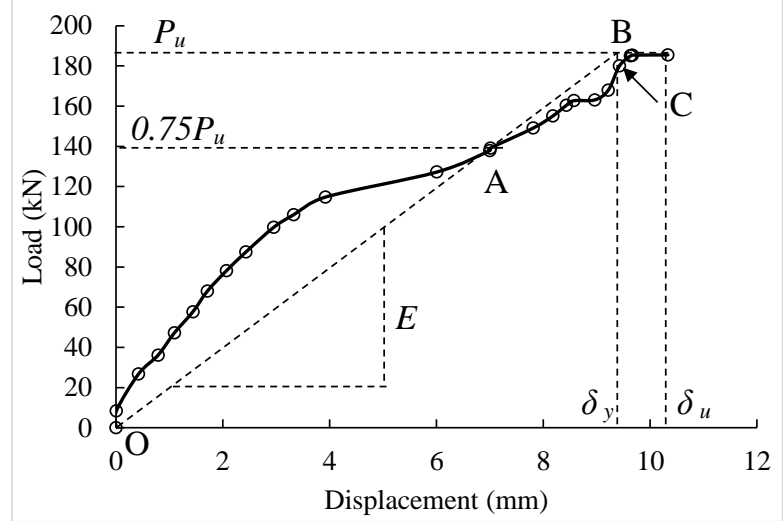

(a) FEM model

Figure 7: Computation of mechanical properties from the $P-\delta$ curves of specimen $\mathrm{C} 1 / \mathrm{S}$

Table 4: Mechanical properties of specimens based on the predicted and experimental results

\begin{tabular}{|c|c|c|c|c|c|c|c|c|c|c|c|c|}
\hline \multirow{2}{*}{ Specimen } & \multicolumn{4}{|c|}{ Secant stiffness, $E(\mathrm{kN} / \mathrm{mm})$} & \multicolumn{4}{|c|}{ Yield strength, $P_{y}(\mathrm{kN})$} & \multicolumn{4}{|c|}{ Yield deflection, $\delta_{y}(\mathrm{~mm})$} \\
\hline & FEM & EXP & $R_{r}$ & State & FEM & EXP & $R_{r}$ & State & FEM & EXP & $R_{r}$ & State \\
\hline $\mathrm{C} 1-\mathrm{S}$ & 19.8 & 25.8 & 0.77 & NA & 176.9 & 152.2 & 1.16 & NA & 9.37 & 6.32 & 1.48 & NA \\
\hline $\mathrm{C} 2-\mathrm{F}$ & 18.3 & 23.3 & 0.79 & NA & 138.8 & 140 & 0.99 & A & 8.67 & 6.73 & 1.29 & NA \\
\hline S1-100 & 20.9 & 21.4 & 0.98 & A & 114.2 & 99.1 & 1.15 & NA & 6.13 & 5.05 & 1.21 & NA \\
\hline S2-75 & 21.2 & 20.7 & 1.02 & A & 118.1 & 120.7 & 0.98 & A & 6.29 & 6.12 & 1.03 & A \\
\hline S3-50 & 26.0 & 20.8 & 1.25 & NA & 116.1 & 120.7 & 0.96 & A & 5.39 & 6.53 & 0.83 & NA \\
\hline F1-100 & 16.9 & 14.8 & 1.14 & NA & 83.2 & 93.8 & 0.89 & NA & 6.16 & 6.91 & 0.89 & NA \\
\hline F2-75 & 16.8 & 19.6 & 0.86 & NA & 118.4 & 113.7 & 1.04 & A & 7.77 & 6.49 & 1.20 & NA \\
\hline $\mathrm{F} 3-50$ & 16.1 & 18.7 & 0.86 & NA & 123.2 & 122.9 & 1.00 & A & 8.39 & 7.18 & 1.17 & NA \\
\hline Reliability & & & & $25 \%$ & & & & $62.5 \%$ & & & & $12.5 \%$ \\
\hline
\end{tabular}

*Note: A - Applicable, NA - Not applicable

From Table 4, it is observed that:

- The model was unable to reliably predict the mechanical properties of the beam. None of the properties reached $80 \%$ satisfactory prediction.

- Nevertheless, the model could predict the strength properties and the ultimate state of the beam (i.e. yield strength, $P_{y}$, ultimate strength, $P_{u}$, and total deflection, $\left.\delta_{u}\right)$ at a higher degree of reliability compared with the other properties like the secant stiffness and the ductility.

- The secant stiffness predicted was generally lower than the experimental results. This affected the accuracy of the prediction of the yield deflection, $\delta_{y}$, and subsequently the ductility, $\Delta$, of the beam.

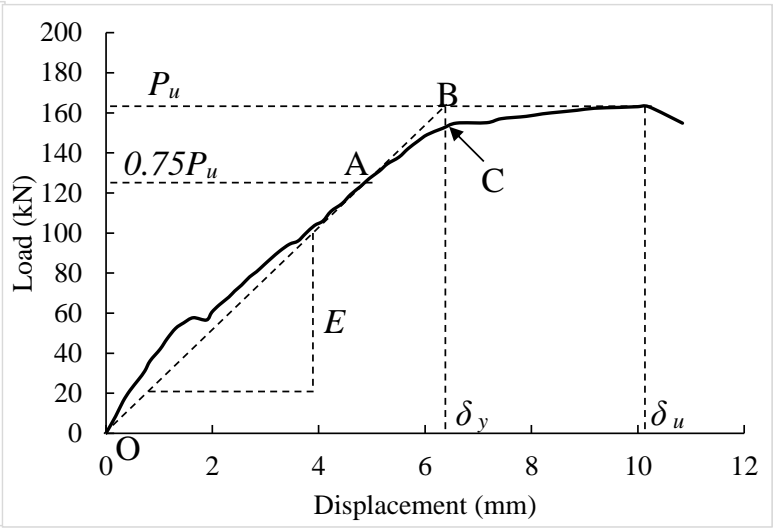

(b) Experimental test

2 


\section{Comparison between Modelling and Experimental Behaviour of Reinforced Concrete Beam with Transverse}

Circular Opening

Table 4: Mechanical properties of specimens based on the predicted and experimental results (Cont.)

\begin{tabular}{|c|c|c|c|c|c|c|c|c|c|c|c|c|}
\hline \multirow{2}{*}{ Specimen } & \multicolumn{4}{|c|}{ Ultimate strength, $P_{u}(\mathrm{kN})$} & \multicolumn{4}{|c|}{ Total deflection, $\delta_{u}(\mathrm{~mm})$} & \multicolumn{4}{|c|}{ Ductility, $\Delta^{*}$} \\
\hline & FEM & EXP & $R_{r}$ & State & FEM & EXP & $R_{r}$ & State & FEM & EXP & $R_{r}$ & State \\
\hline C1-S & 185.5 & 163.11 & 1.14 & NA & 10.331 & 10.2 & 1.01 & A & 1.1 & 1.61 & 0.68 & NA \\
\hline $\mathrm{C} 2-\mathrm{F}$ & 158.6 & 156.81 & 1.01 & A & 9.988 & 10.42 & 0.96 & A & 1.15 & 1.55 & 0.74 & NA \\
\hline S1-100 & 128.1 & 108.03 & 1.19 & NA & 7.349 & 5.76 & 1.28 & NA & 1.2 & 1.14 & 1.05 & A \\
\hline $\mathrm{S} 2-75$ & 133.3 & 126.71 & 1.05 & A & 7.748 & 6.99 & 1.11 & NA & 1.23 & 1.14 & 1.08 & A \\
\hline S3-50 & 140.2 & 135.81 & 1.03 & A & 9.609 & 9.34 & 1.03 & A & 1.78 & 1.43 & 1.24 & NA \\
\hline F1-100 & 104.1 & 102.33 & 1.02 & A & 9.027 & 8.61 & 1.05 & A & 1.47 & 1.25 & 1.18 & NA \\
\hline F2-75 & 130.6 & 127.21 & 1.03 & A & 8.855 & 8.3 & 1.07 & A & 1.14 & 1.28 & 0.89 & NA \\
\hline F3-50 & 135.1 & 134.3 & 1.01 & A & 9.716 & 10.07 & 0.96 & A & 1.16 & 1.40 & 0.83 & NA \\
\hline Reliability & & & & $75 \%$ & & & & $75 \%$ & & & & $25 \%$ \\
\hline
\end{tabular}

*Note: The ductility was computed by dividing the total deflection, $\delta_{u}$, by the deflection at yield, $\delta_{y}$.

\section{Parametric response}

Figure 8 compares the parametric responses of the model and experimental results, particularly the effects of the opening size on the beam performance. In general, the predicted parametric responses for the beam capacity and total deflection, as represented by the trend of the curves, were somewhat similar to the experimental results. It deviated significantly for the other mechanical properties.

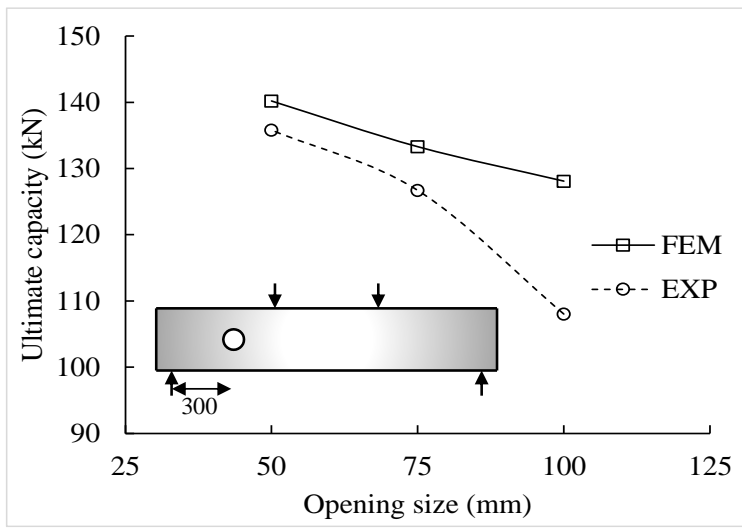

(a) Ultimate capacity

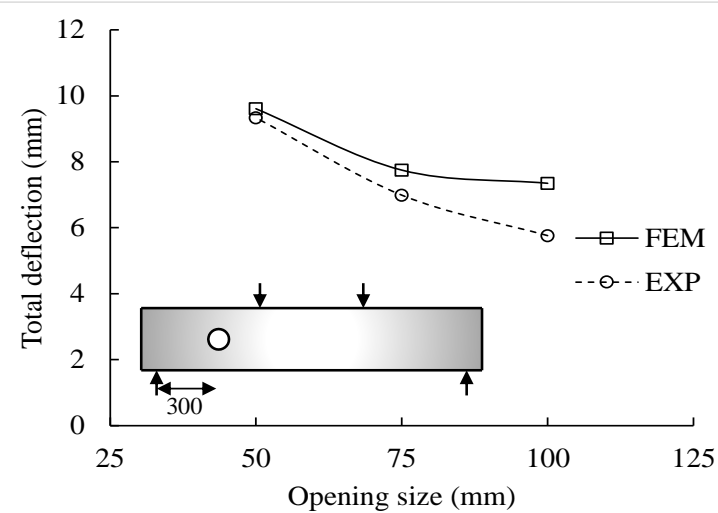

(b) Total deflection of beam

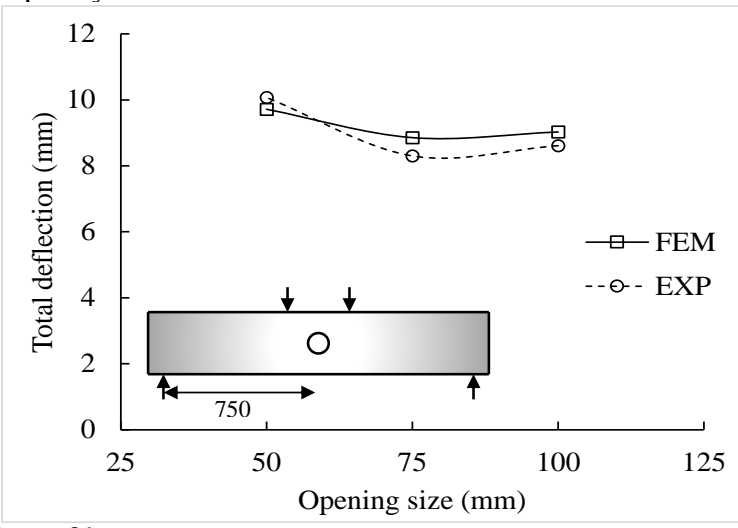

In principles, the opening was found affecting the strength and deflection of beam. A larger opening size led to a lower ultimate capacity, yield strength and total deformation of beam. The strength of beam was more significantly affected by the opening size when it was placed at the mid-span. The strength reduction was more drastic than when it is placed near to the support. These findings were in-line with the experimental results. The other responses varied slightly from the experimental results.

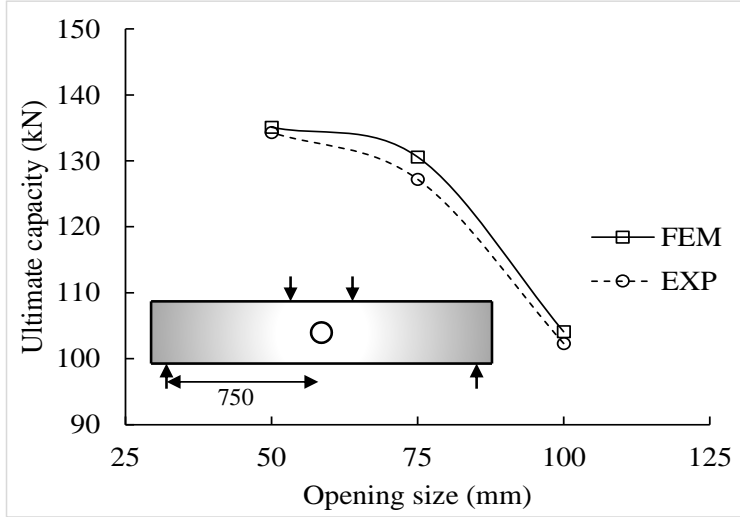

Figure 9: Effects of opening size on beam performance 

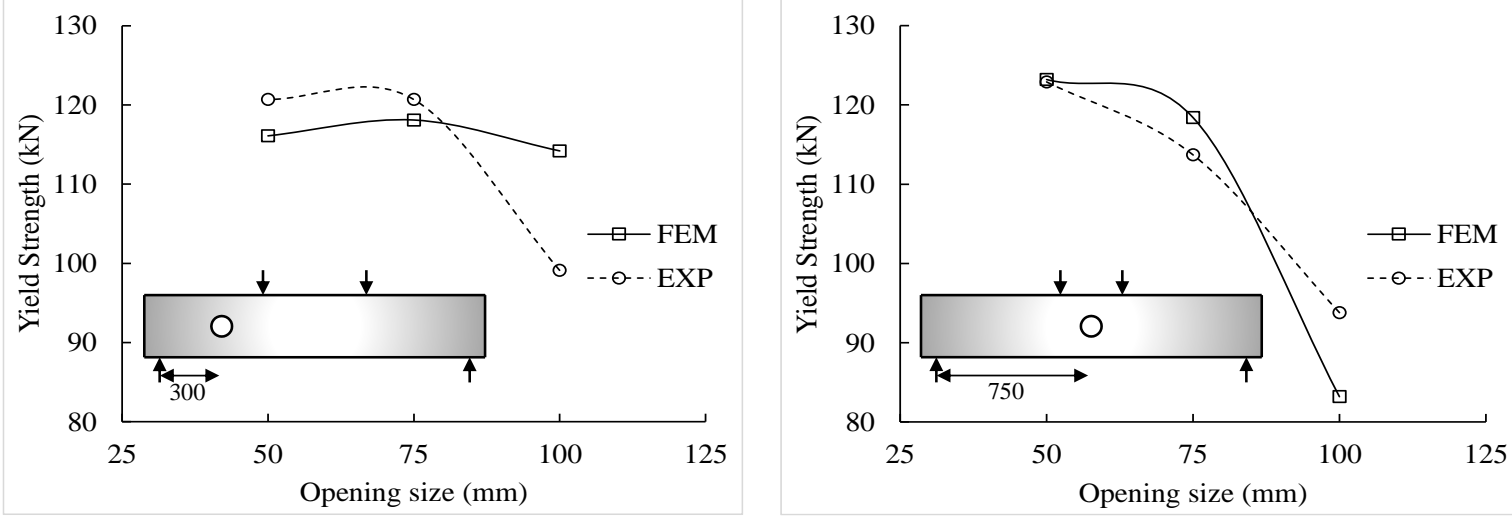

(c) Yield strength of beam
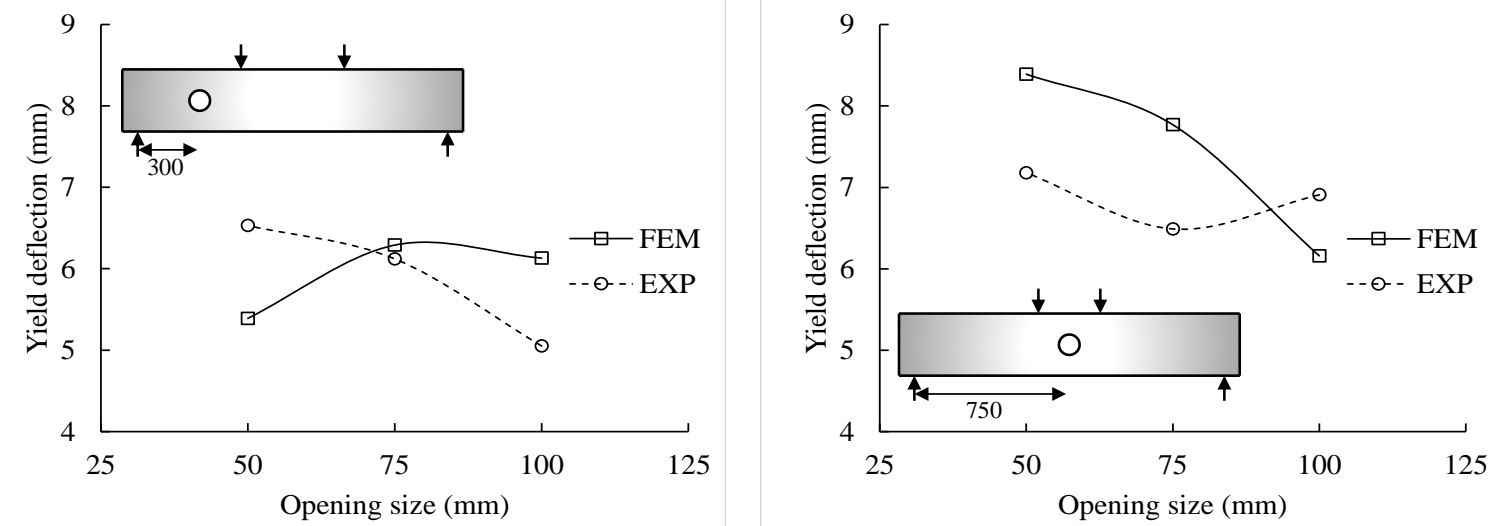

(d) Yield deflection of beam
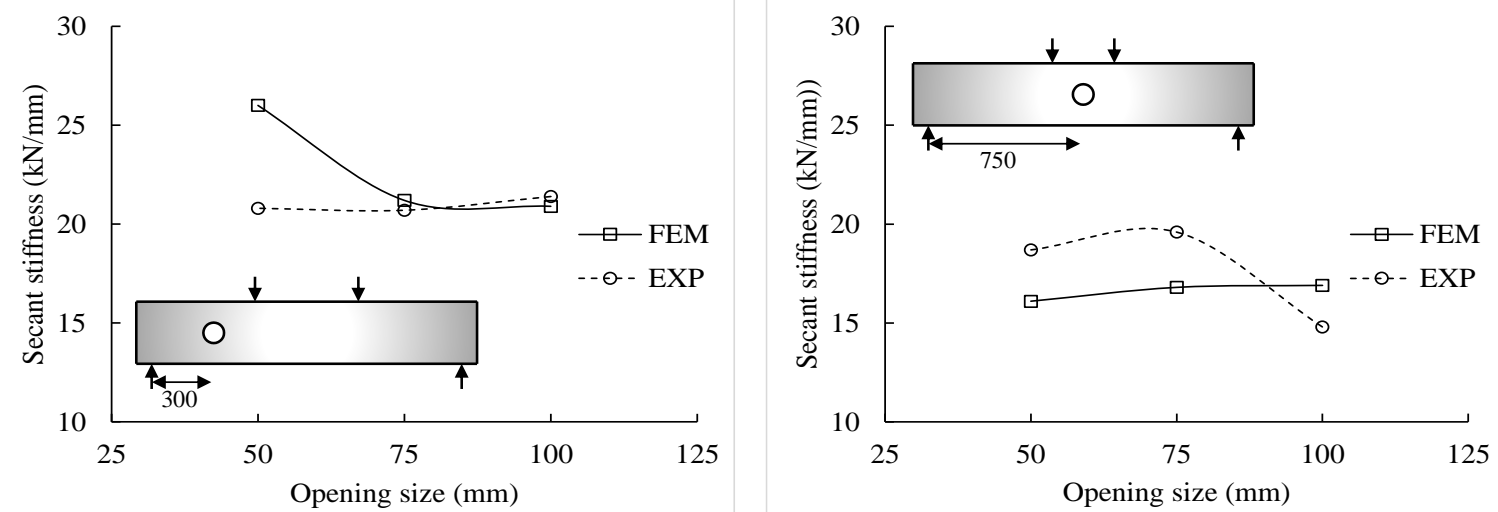

(e) Secant stiffness of beam
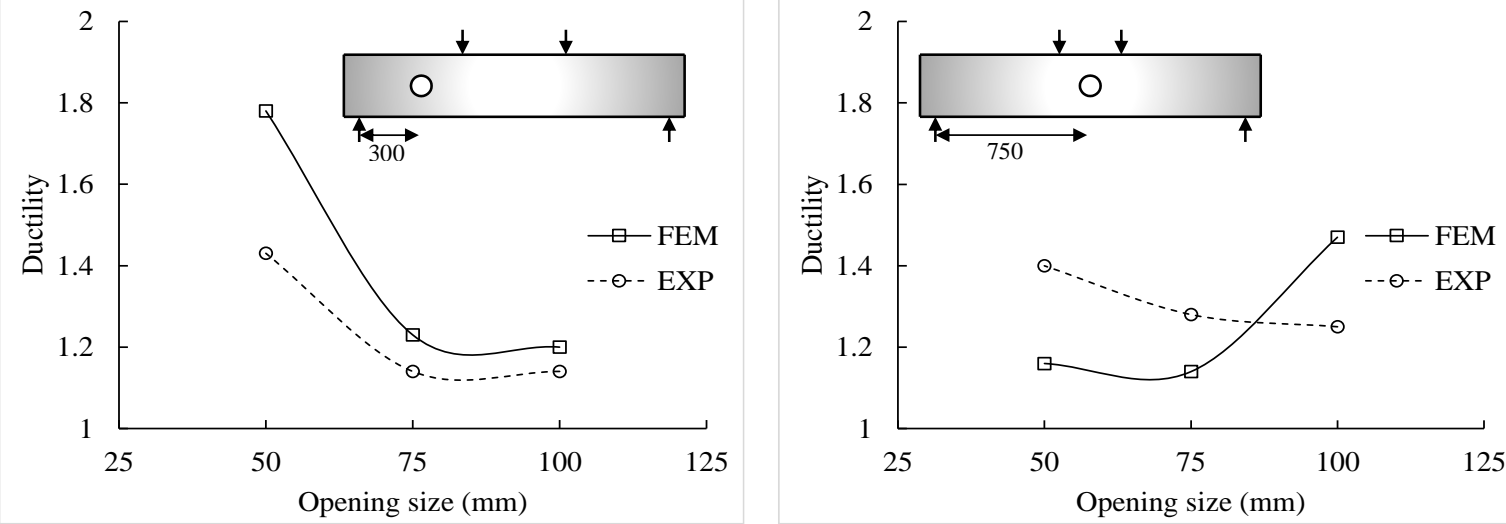

(f) Ductility of beam

Figure 9: Effects of opening size on beam performance (cont.) 


\section{Comparison between Modelling and Experimental Behaviour of Reinforced Concrete Beam with Transverse Circular Opening}

\section{CONCLUSION}

This paper presents a validation analysis of a FEM model developed to simulate the response of RC beams with a transverse opening. The reliability of the model was evaluated in terms of the load-displacement response, mechanical properties, and the parametric response.

Although the predicted responses of the specimens were somewhat close to the experimental results, the reliability of the model was still questionable. Should the model be used for simulating the actual response of the beam, particularly for further research studies or industrial applications, it should be used with cautions. This includes (a) to strategically cross-check of the predicted results with the actual responses, (b) to apply some factors of safety to maintain an acceptable degree of conservativeness, and (c) to adopt only the results found to have a higher degree of reliability.

Alternatively, one could relook into the model, revise as necessary. This includes fine-tuning (a) the material properties, (b) the boundary conditions, (c) the bonding conditions, (d) meshing size, and etc., as necessary, so that it more closely resembles the actual response of a beam.

\section{ACKNOWLEDGMENT}

This work was supported by the Research Grants of University College of Technology Sarawak, UCTS/RESEARCH/2/2018/02.

\section{REFERENCES}

[1] Mansur, M.A. and K.H. Tan, 1999. Concrete beams with openings: Analysis and design, Taylor \& Francis.

[2] Mansur, M.A., 2006. Design of reinforced concrete beams with web openings. Proceeding of 6th AsiaPacific Structural Engineering and Construction Conference (APSEC 2006). Kuala Lumpur, Malaysia. p. 104-20.

[3] Osman, M.R., K. Metwally and M.S. Wafaa., 2015. Proposed recommendations for the design of reinforced concrete beams with openings. Proceeding of The 2015 World Congress on Advances in Structural Engineering and Mechanics (ASEM15). Incheon, Korea.

[4] Herrera L, S. Anacleto-Lupianez and A. Lemnitzer, 2017. Experimental performance of RC moment frame beams with rectangular openings. Engineering Structures. 152: 149-67.

[5] Aykac B, I. Kalkan, S. Aykac and Y.E. Egriboz, 2013. Flexural behavior of RC beams with regular square or circular web openings. Engineering Structures. 56: 2165-2174.
[6] Oukaili N.K. and A.H Al-Shammari, 2014. CFRP strengthening of RC beams with multiple openings subjected to static and impact loads. Advances in Structural Engineering. 17: 1747-1760.

[7] Mamatha S, N. Changler, P. Singore, S.S. Jevoora and L. Geetha, 2017. The study of behavior of RC beam with transverse opening under static load. International Journal of Engineering Science and Computing. 7: 13480-13484.

[8] El-Kareim Shoeib A and A. El-Sayed Sedawy 2017. Shear strength reduction due to introduced opening in loaded RC beams. Journal of Building Engineering. 13: 28-40.

[9] Osman B.H., E. Wu, B. Ji and S.S. Abdulhameed, 2016. Shear behavior of Reinforced Concrete (RC) beams with circular web openings without additional shear reinforcement. KSCE Journal of Civil Engineering. 21: 296-306.

[10] Somes N.F. and W.G. Corley, 1974. Circular openings in webs of continuous beams. Special Publication. 42.

[11] Mohamed A.R., M.S. Shoukry and J.M Saeed, 2014. Prediction of the behavior of reinforced concrete deep beams with web openings using the finite element method. Alexandria Engineering Journal. 53: 329-39.

[12] Amiri S. and Masoudnia R., 2011. Investigation of the opening effects on the behavior of concrete beams without additional reinforcement in opening region using FEM method. Australian Journal of Basic and Applied Sciences. 5: 617-627.

[13]Latha M.S., B.M and Naveen Kumar, 2017. Behavior of reinforced concrete beam with opening. International Journal of Civil Engineering and Technology (IJCIET). 8: 581-593.

[14]Al-sheikh S.A., 2014. Flexural behavior of RC beams with opening. Concrete Research Letters. 5: 812-824.

[15] Saksena N.H. and P.G. Patel, 2013. Experimental study of reinforced concrete beam with web openings. International Journal of Advanced Engineering Research and Studies. 2: 66-68.

[16] Tang H.S, 2018. The behaviour of reinforced concrete beam with circular opening under incremental flexural and shear load. Final Year Project, University College of Technology Sarawak, Sibu, Sarawak.

[17]Ling J.H., H.S. Tang, W.K. Leong, H.T. Sia., 2019. Effects of transverse circular opening in reinforced concrete beam subjected to incremental static load. Borneo Journal of Sciences and Technology. 1:3944. 